\title{
Conditioned sucking in the human newborn
}

\author{
Lewis P. Lipsitt and Herbert Kaye \\ BROWN UNIVERSITY
}

\begin{abstract}
Classical conditioning of the sucking response was demonstrated. Sucking in response to a tone was greater in infants who received paired presentations of the tone and a sucking device than in infants who received unpaired presentations of the same stimuli.
\end{abstract}

\section{Problem}

To determine whether classical conditioning is possible within the first days of human life, a tone was used as a conditioning stimulus (CS), and insertion of a nipple in the baby's mouth to elicit sucking movements constituted the unconditioned stimulus (UCS). If conditioning takes place, more sucking to the tone should occur following paired presentations of CS and UCS (experimental group, E) than following unpaired presentations (control group, C).

\section{Method}

Two groups of 10 hospital Ss in their third or fourth day were studied between 8 and 9:15 a.m., at least $3 \mathrm{hrs}$. after the previous feeding. For both groups, the CS was a low-frequency, loud (about $93 \mathrm{db}$ ) square-wave tone with a fundamental component of 23 cps and lasting $15 \mathrm{sec}$. For Group E, the nipple 2 was inserted in the infant's mouth 1 sec. after onset of the CS and remained to the end of the 15-sec. CS. For Group C, the CS and UCS were not paired; the nipple was inserted for $14 \mathrm{sec}$. approximately $30 \mathrm{sec}$. following offset of the CS.

All Ss first received 5 basal trials of CS alone. Presence and number of sucking movements to each 15-sec. tone were recorded independently by 2 Os. These trials were administered approximately $1 \mathrm{~min}$. apart. Both groups then received 25 training trials,

${ }^{1}$ The writers thank Mrs. Dorothy Westlake for her assistance. This study was carried out as part of a project entitled Sensory Discrimination and Learning in Human Infants under a USPHS grant (NB-04268) to Lewis P. Lipsitt. The writers are indebted to the staff of the Providence Lying-In Hospital for their co-operation.

2 The non-nutritive nipple used was an automatic device for the recording of sucking responses developed by Grunzke (1961) for work with monkeys. For work with humans, Levin and Kaye (1964) adapted this stainless-steel mouthpiece, shaped like a nipple and containing a small lever attached to a microswitch, by covering it with a sterile rubber nipple. As the infant sucks, the lever is depressed and released, producing digital blips on a polygraph record. every 5th trial being a test in which sucking responses to the CS alone were recorded. For Group E, CS and UCS were paired for $14 \mathrm{sec}$. on the 20 conditioning trials. On these trials, Group $\mathrm{C}$ received the CS and UCS stimulations with a variable interval of 25-45 sec. (average, $30 \mathrm{sec}$.) between offset of $\mathrm{CS}$ and introduction of UCS. For Group E, intertrial interval was $1 \mathrm{~min}$.; for Group $\mathrm{C}$ about $30 \mathrm{sec}$. Thus the conditioning session for Group $\mathrm{E}$ took approximately $31 \mathrm{~min}$.; for Group C, about $38 \mathrm{~min}$.

Following the conditioning period, all Ss received no less than 10 nor more than 30 extinction trials like the basal trials, these being discontinued when no responses occurred for 3 successive trials, the extinction criterion.

\section{Results}

O agreement was high for both measures, the results being essentially identical when each O's results were considered independently. Averages for both Os are plotted in Fig. 1 for the three phases of the study: 5 basal trials, 5 CS trials during conditioning, and 2 blocks of 5 extinction or test trials. The per cent measure, indicating proportions of trials in which sucking occurred during CS-alone presentations, showed an increase for Group $\mathrm{E}$ from beginning to end of the session, while this measure leveled off for Group C. A similar trend was present for the number-of-sucks measure. Analyses of variance for both measures yielded highly significant interactions between groups and phases $[\mathrm{F}(3,54)=19.4$ and $12.3, \mathrm{p}<.001$, respectively], indicating increasing differences between groups over time. Individual Ss in Group $\mathrm{E}$ showed a significantly greater amount of change from basal to extinction periods in both per cent of response and number of sucks $[\mathrm{t}(18)=2.14$ and $\mathrm{t}(18)=2.41, \mathrm{p}<.05$, respectively]. Finally, the trials-to-criterion measure in extinction showed that Group $E$ gave responses on the average of 24.1 of 30 trials compared with 11.1 for Group $\mathrm{C}[\mathrm{t}(18)=2.42$, $\mathrm{p}<.05]$.

\section{Diseussion}

The study design attempted to control for sensitization or pseudoconditioning (Wickens \& Wickens, 1940) by giving both groups identical stimulation but in different CS-UCS temporal relationships. There are two indications that this procedure did not completely eliminate such an effect: (1) Group C gave 

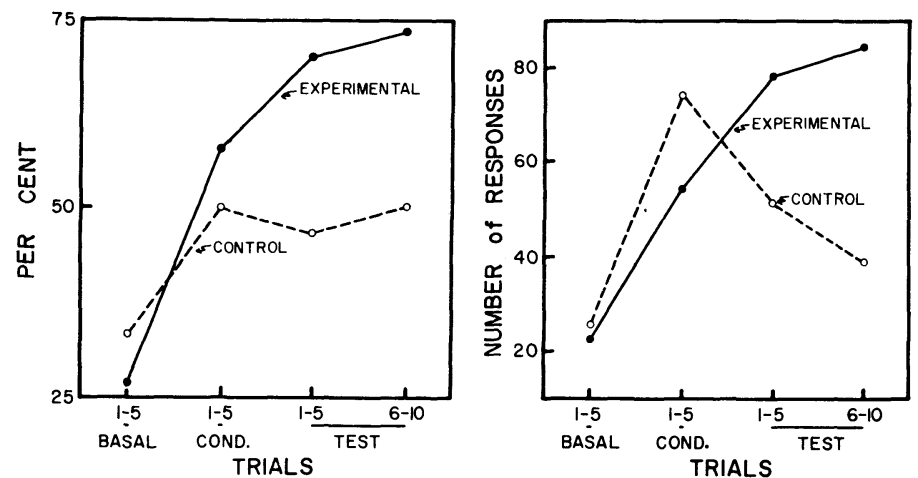

Fig. 1. Percentage and number of sucking responses to the CS (tone) in the Experimental and Control Groups.

slightly (not significantly) more responses to CS than Group E during the conditioning period, and (2) Group $\mathrm{C}$ responded more during the extinction phase than during the basal phase. When the individual averages from the basal trials of Group $\mathrm{C}$ are compared with averages from the first 10 extinction trials, the $t$ is 2.45 for the per cent measure $(\mathrm{df}=9, \mathrm{p}<.05)$ and for the number-of-sucks measure, the $t$ is 2.59 $(p<.05)$. Thus the Group $C$ treatment was itself effective in increasing response, possibly due to (1) sensitization, (2) the unlikely possibility of trace conditioning having occurred in Group C, or (3) increase in hunger or other arousing condition, 35-40 min. having elapsed between the basal and extinction periods. Regardless, it has been established that the paired stimulation administered to Group E increased response more than did the control condition.

While 20 paired presentations of CS and UCS constitute a relatively small number of trials, the frequency of sucking during presentation of the UCS is such as to produce many "pairings" within each trial. Groups E and C responded with means of 13.1 and 13.0 sucks, respectively, per nipple presentation, and they did not differ over trials in numbers of sucks made to successive UCS presentations. If each sucking response is considered independently, then an average of 260 "pairings" of CS and UCS occurred in the conditioning session for the experimental Ss. Thus sucking is an efficient response for administering many paired CS-UCS presentations in a brief period.

These data agree with a much earlier experiment by Marquis (1931) and, more recently, with Papousek (1961) that conditioning of responses involving mouthstimulation can occur in newborns, and contrast with reservations expressed by Kessen (1963) and Scott (1963). While age-determined changes in conditioning rate apparently occur (Kantrow, 1937; Morgan and Morgan, 1944; Papousek, 1961), failures to establish conditioning in neonates may be due as much to the use of ineffective experimental techniques as to chronological or neurophysiological deficiencies.

\section{References}

GRUNSKE, M. E. A liquid dispenser for primates. J. exp. Anal. Beh., 1961, 4, 326.

KANTROW, R. W. An investigation of conditioned feeding responses and concomitant adaptive behavior in young infants. Univ. Ia. Stud. Child Welf., 1937, 13, No. 3 .

KESSEN, W. Research in the psychological development of children. Merrill Palmer Quart., 1963, 9, 83-94.

LEVIN, G. R., and KAYE, H. Non-nutritive sucking by human neonates. Child Developm., 1964. In press. MARQUIS, D. P. Can conditioned responses be established in the newborn infant? J.genet. Psychol., $1931,39,479-492$.

MORGAN, J. J. B., and MORGAN, S. S. Infant learning as a developmental index. J. genet. Psychol., 1944, $65,281-289$.

PAPOUSEK, H. Conditioned head rotation reflexes in infants in the first months of life. Acta Pediatr., $1961,50,565-576$.

WICKENS, D. D., and WICKENS, C. A study of conditioning in the neonate. J.exp. Psychol., 1940, 26, 94-102. 